\title{
Preparation and Characterization of Hydrogels with Potential for Use as Biomaterials
}

\author{
Mônica Beatriz. Thürmer*, Carlos Eduardo Diehl, Fábio José Bento Brum, Luís Alberto dos Santos \\ Materials Department, Federal University of Rio Grande do Sul - UFRGS, \\ Av. Bento Gonçalves, 9500, CEP 91509-900, Porto Alegre, RS, Brazil
}

Received: June 26, 2013; Revised: June 23, 2014

\begin{abstract}
Hydrogels have been extensively explored for biomedical applications due to their ability to absorb high water content in its structure, which gives excellent biocompatibility. This work aims at obtaining biocompatible hydrogels with potential for use in increasing the mechanical strength of bone substitutes, or controlled drug release. Poly (N-vinyl-2-pyrrolidone) hydrogels were prepared by free radical polymerization with and without the addition of acrylic acid. Azobisisobutyronitrile and ammonium persulfate were used as initiator and N,N-methylenebisacrylamide was used as the crosslinking agent. The characterization of the hydrogels was performed by thermogravimetric analysis, differential scanning calorimetry, infrared spectroscopy and swelling properties. The results obtained demonstrate different degrees of crosslinking and swelling of up to $490 \pm 30 \%$. The different properties of the hydrogels suggest different applications.
\end{abstract}

Keywords: biocompatible, hydrogel, PVP, PAA, polymerization

\section{Introduction}

Polymers are today the largest group of materials used for biomedical purposes. They are used separately and/ or in combination with other materials. The main areas of today's applications of hydrogels materials include wound dressing, drug delivery systems, transdermal systems, dental applications, injectable polymers, implants and ophthalmic applications ${ }^{1}$. Hydrogels are polymer-based three dimension network systems that are formed by chemical or physical crosslinking of individual polymer chains, which can absorb large amounts of water and biological fluids in their structure $^{2,3}$. Limited water-absorption capabilities (ca. 5-10 $\mathrm{wt} \%$ ) of certain polymeric networks, exhibit the ability to retain the drugs for longer periods ${ }^{4,5}$.

The hydrogels have been extensively exploited for biomedical applications due to their high water content which imparts excellent biocompatibility ${ }^{6,7}$. Drug delivery systems developed for many different purposes have been based on hydrogels, mostly the neutral hydrogels. In addition, hydrogels have been applied in gel casting approach to reinforce $\alpha$-tricalcium phosphate-based calcium phosphate cement during the first stage of setting, for use as biomaterial ${ }^{8,9}$.

$\mathrm{N}$-vinyl-2-pyrrolidone (VP) is a water-soluble, nonionic monomer that can be used to prepare hydrogels ${ }^{10}$. VP-based materials have been of interest in, for example, biomedical applications ${ }^{11,12}$. In recent years, polyacrylic acid (PAA) and its copolymers have often been used as carriers in drug release systems, because of their multifunctional nature, unique properties and good biocompatibility ${ }^{13,14}$.

Several studies of the water swelling and drug release behaviours of poly(AA-co-VP) hydrogels have been reported $^{15-17}$. In these hydrogels strong hydrogen bonds can be formed between the AA and VP constituents ${ }^{16}$.

*e-mail: monicathurmer@yahoo.com.br
These copolymer hydrogels have been shown to display properties ranging between those of the two homopolymers and reported that the extent of swelling depends on the copolymer composition and crosslink density.

In the current investigation, we have attempted to develop a biodegradable and biocompatible hydrogel with potential for use in increased resistance of calcium phosphate cement implants or as controlled drug delivery. New formulations of hydrogels have been developed using N-Vinyl-2-pyrrolidone with and without acrylic acid, employing azobisisobutyronitrile or ammonium persulfate as initiator, by the free radical polymerization method. N,Nmethylenebisacrylamide was used as crosslinking agent. The aim was to compare the properties obtained by the different formulations prepared. This comparison is not reported in the literature and can be used for the development of future work. The two monomers used have very fair reputation as non-toxic and biocompatible materials ${ }^{18}$. Hydrogels based on poly (vinylpyrrolidone) have been applied successfully as local dressings on wound treatments, such as burns, skin's ulceration and postoperative dressings ${ }^{19}$ or controls release system for drug delivery ${ }^{20,21}$ because of their biocompatibility with the human body. Moreover, polyacrylic acid is known to be a good mucoadhesive and may increase the transit time of formulation, in drug delivery systems ${ }^{22}$. These hydrogels were characterized by TGA, DSC, FTIR and equilibrium swelling studies.

\section{Experiment}

\subsection{Material}

The hydrogels polymerization occurred by free radical polymerization using N-vinyl-2-pyrrolidone (NVP) (Merck, Germany) and acrylic acid anhydrous (AA) (Aldrich, 
Germany). As initiator was used azobisisobutyronitrile (AIBN) (Aldrich, Germany) or ammonium persulfate (AP) (Merck, Brazil). The bifunctional compound $\mathrm{N}, \mathrm{N}^{\prime}$-methylenebisacrylamide (MBAM) (Aldrich, Germany) were used as crosslinking agent and N,N,N',N'tetramethylethylenediamine (TEMED) was used as catalyst.

\subsection{Preparation of hydrogels}

The composition of the hydrogels is shown in Table 1. The solutions were warm to $80{ }^{\circ} \mathrm{C}$ washed and lyophilized for subsequent characterization.

\subsection{Hydrogels characterization}

\subsubsection{Thermogravimetric Analysis (TGA)}

Thermal stability was evaluated in a thermogravimetric analyzer TGA 2050 (TA Instruments). The samples were heated to $970{ }^{\circ} \mathrm{C}$ at the rate of $10{ }^{\circ} \mathrm{C} \cdot \mathrm{min}^{-1}$, under flowing nitrogen of $20 \mathrm{ml} \cdot \mathrm{min}^{-1}$.

\subsubsection{Differential Scanning Calorimetry (DSC)}

DSC measurements were performed using a DSC Q20 (TA Instruments) at $10^{\circ} \mathrm{C} \cdot \mathrm{min}^{-1}$. Nitrogen was the carrier gas, and its flow rate was $50 \mathrm{~mL} \cdot \mathrm{min}^{-1}$. The second heating cycles of these runs were used to determine the $\mathrm{Tg}$.

\subsubsection{Infrared spectroscopic analysis (FTIR)}

Infrared spectra of hydrogels were obtained using Spectrum 1000 (PerkinElmer) spectrometer in the range of $400-4000 \mathrm{~cm}^{-1}$ using $\mathrm{KBr}$ discs.

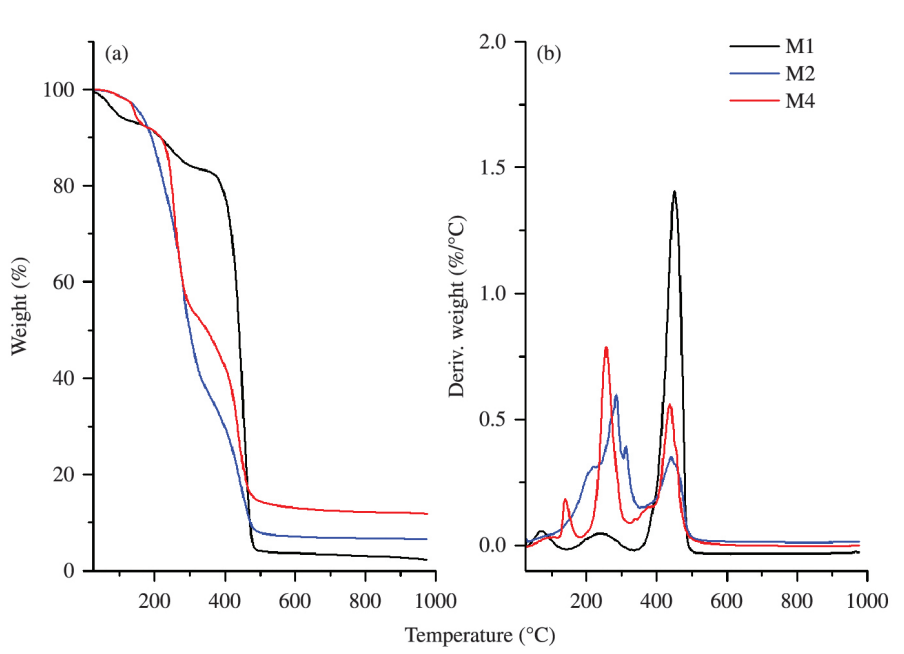

\subsubsection{Swelling behavior studies of hydrogels}

The equilibrium swelling of the hydrogels was determined by swelling the hydrogels samples (lyophilized previously) in water distilled at room temperature until equilibrium was attained. Three samples were used for each swelling determination. The swollen weight of the pellet was determined by blotting of the pellet every hour until equilibrium was attained. The percent swelling was calculated by the Equation 1 .

$\%$ Swelling $=\frac{W_{t}-W_{o}}{W_{o}} \times 100$

where $\mathrm{W}_{\mathrm{o}}$ is the initial weight and the $\mathrm{W}_{\mathrm{t}}$ is the final weight of the sample.

\section{Results and Discussion}

The hydrogel system consists of Poly (N-vinyl-2pyrrolidone) which is slowly degradable and has a high glass transition temperature. Polyacrylic acid was also included in the system which imparts $\mathrm{pH}$ sensitivity. This pendent acidic moiety changes ionization in response to the changes in $\mathrm{pH}$. The hydrogels also displays $\mathrm{pH}$ sensitive nature which can be exploited for site specific controlled drug delivery.

The composition used in the M3 formulation sample didn't result in polymerization, therefore was not possible to characterize this sample.

\subsection{Thermogravimetric Analysis (TGA)}

The thermal analysis of hydrogels by TGA (Figure 1) demonstrates the stability of the polymeric matrix to $200{ }^{\circ} \mathrm{C}$. For the M1 sample there was initial weight loss

Figure 1. Thermo-gravimetric curve (a) and derivative thermo-gravimetric curve (b) scan of hydrogels in nitrogen.

Table 1. Composition of the hydrogels.

\begin{tabular}{ccccccc}
\hline \multirow{2}{*}{ Sample } & NVP & AA & MBAM & TEMED & AIBN & AP \\
\cline { 2 - 7 } & $\left(\mathbf{m o l . L}^{-1}\right)$ & $\left(\mathbf{m o l . L}^{-1}\right)$ & $(\boldsymbol{\%})$ & $(\boldsymbol{\%})$ & $(\boldsymbol{\%})$ & $(\boldsymbol{\%})$ \\
\hline M1 & 2.6 & - & 2.0 & 0.2 & 3.0 & - \\
M2 & 2.6 & 1.0 & 2.0 & 0.2 & 3.0 & - \\
M3 & 2.6 & - & 2.0 & 0.2 & - & 6.0 \\
M4 & 2.6 & 1.0 & 2.0 & 0.2 & - & 6.0 \\
\hline
\end{tabular}


due to loss of moisture in the gel from $60-120{ }^{\circ} \mathrm{C}$. The discontinuous TGA curve also indicates the not formation of interpolymeric matrix.

Since the proposed hydrogel system is intended to be used for the release of drug from the varying medium or as a booster for use as a biomaterial, and the release process is normally carried out at physiological temperature $37^{\circ} \mathrm{C}$, the polymer is totally stable in the vicinity of room temperature which normally varies between 27 and $38^{\circ} \mathrm{C}$.

\subsection{Differential Scanning Calorimetry (DSC)}

Figure 2 shows the thermograms of the samples prepared, obtained by differential scanning calorimetric and the Table 2 presents the thermal characteristics of hydrogels. The glass transition temperature of each sample was calculated as the midpoint of the transition. Three DSC runs of each sample were taken to determine the average $\mathrm{Tg}$ value and the standard derivation. From the literature, the Tg of PVP having an $M w$ value of $1.2 \times 10^{6}$ is $178{ }^{\circ} \mathrm{C}^{23}$ and the experimental value of M1 sample (without AA) is $173.51{ }^{\circ} \mathrm{C}$, which agrees well with the literature value. $\mathrm{Wu}$ and Freeman ${ }^{24}$ found that, in the temperature range of 0-350 ${ }^{\circ} \mathrm{C}$, was not observed $\mathrm{Tg}$ in a polymerized MBAM sample, probably due to its very high crosslink density. Generally, in highly crosslinked polymers, Tg may be difficult or impossible to observe due to restriction on mainchain motion by the crosslinks.

Based upon these results and the large difference in reactivity ratio between NVP and MBAA, two regions (NVP-rich and MBAA-rich) form during polymerization. Due to the dense crosslinking of MBAA-rich regions, there was no $\mathrm{Tg}$ related to crosslinked MBAA observed in the polymer network, and only one $\mathrm{Tg}$, corresponding to that of the NVP-rich regions, was observed.

Analyzing the thermal characteristics of hydrogels, we can verify that the samples showed a single $\mathrm{Tg}$ and this is affected by the presence of the AA and also by the initiator used. The presence of AA resulted in the decrease of $\mathrm{Tg}$ in both cases. The reduction was more significant when used Ammonium Persulfate as initiator.

\subsection{Infrared spectroscopic analysis (FTIR)}

The hydrogels were characterized by FT-IR spectroscopy as showed in Figure 3. Száraz and Forsling ${ }^{25}$ reported two very strong bands in the IR spectrum of pure liquid NVP that are sensitive to extent of reaction. The first, at $1629 \mathrm{~cm}^{-1}$, is ascribed to $\mathrm{C}=\mathrm{C}$ bond stretching vibrations. The second, attributed to carbonyl stretching $(\mathrm{C}=\mathrm{O})$, is located at $1706 \mathrm{~cm}^{-1}$. Greever et al. ${ }^{26}$ also identified characteristic IR absorptions for NVP at $1623 \mathrm{~cm}^{-1}(\mathrm{C}=\mathrm{C})$ and $1700 \mathrm{~cm}^{-1}$ $(\mathrm{C}=\mathrm{O})$. The non-appearance of these bands indicates polymerization of the NVP monomer, and a broad $\mathrm{C}=\mathrm{O}$ bond appears at $1650 \mathrm{~cm}^{-1}$ in polyvinylpyrrolidone (PVP). The characteristic IR absorption at $\sim 1630 \mathrm{~cm}^{-1}$ is assigned to the $\mathrm{C}=\mathrm{C}$ bond stretching vibration of $\mathrm{MBAM}^{27}$. The infrared region of $3800-3000 \mathrm{~cm}^{-1}$ is attributed to $\mathrm{OH}$ stretch mode of water.

Consistent with the literature discussed above, the disappearance of the characteristic NVP and MBAA absorptions in the FTIR spectra of the crosslinked NVP films and the appearance of a broad $\mathrm{C}=\mathrm{O}$ absorption, characteristic of PVP, at $1650 \mathrm{~cm}^{-1}$ both suggest that the polymerization conditions were sufficient to essentially completely react the double bonds in the NVP and MBAA. The appearance of an absorption in the region of $1550 \mathrm{~cm}^{-1}$ (amide II band) suggests that the MBAM was successfully crosslinked with NVP during polymerization.

According to Devine and Higginbotham ${ }^{28}$, the carbonyl group of PVP exhibits a stretching vibration peak between 1650 and $1680 \mathrm{~cm}^{-1}$ and the carbonyl group of carboxylic acid group on the PAA chain exhibits a peak at approximate $1750 \mathrm{~cm}^{-1}$. When the carbonyl group forms intermolecular bond (such as hydrogen bond), there is a negative shift exhibited in the FTIR Spectrum, that can be observed in M4 sample. It is also evidence that a small shoulder

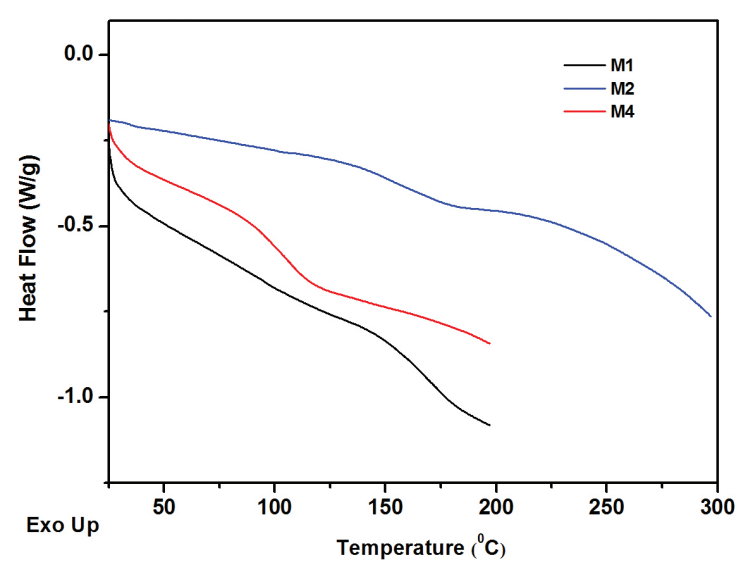

Figure 2. Differential scanning calorimetric thermogram of hydrogels.

Table 2. Thermal characteristics of hydrogels.

\begin{tabular}{cccc}
\hline Sample & $\mathbf{T}_{\text {dmax }}\left({ }^{\circ} \mathbf{C}\right)$ & $\mathbf{T g}\left({ }^{\circ} \mathbf{C}\right)$ & Residue at $976{ }^{\circ} \mathbf{C ~ ( \% )}$ \\
\hline M1 & 450.41 & 173.51 & 2.24 \\
M2 & 441.33 & 151.67 & 6.56 \\
M4 & 437.49 & 106.21 & 11.82 \\
\hline
\end{tabular}

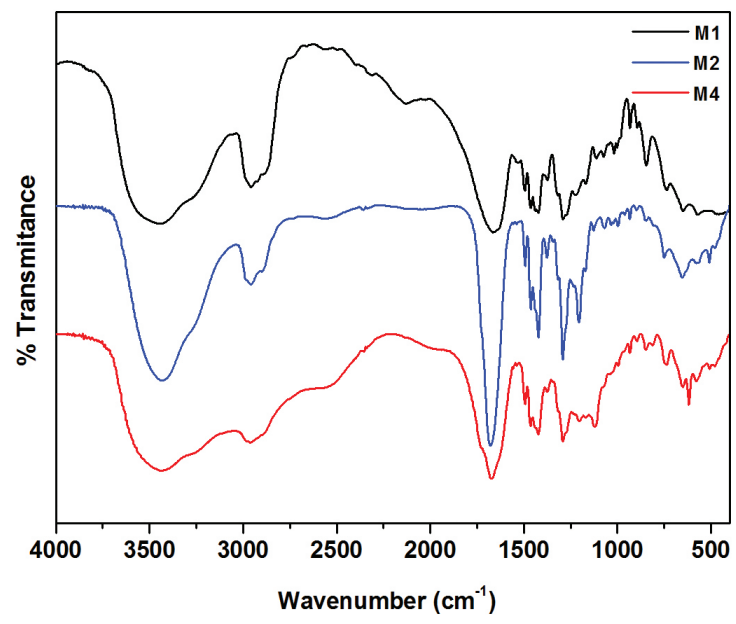

Figure 3. Fourier transform infrared spectrum of hydrogels. 
appeared in this sample at about $1730 \mathrm{~cm}^{-1}$ corresponding to stretching vibration of carbonyl group of carboxylic acid group on the PAA chain, which further illustrated that some intermolecular hydrogen bond did occur and the complexation formed between PVP bead and PAA. Therefore, this suggests that, for the M4 sample, may have been the formation of a semi-interpenetrating network. However this did not occur in this sample, because there was a decreased in the $\mathrm{Tg}$ and was totally dissolved in water shortly after immersion, as shown below.

\subsection{Swelling behavior studies of hydrogels}

In the equilibrium swelling studies was possible to observe different swelling capacities. The M1 sample presented swelling capacities very high, around $490 \pm 30 \%$, however the hydrogel integrity was lost with the time and the M2 sample presented around $90 \pm 2 \%$ swelling at equilibrium indicating a high degree of crosslinking. We know that the increase in the crosslinked density result in a lower equilibrium swelling degree ${ }^{29}$. The M4 sample showed a low degree of crosslinking, and dissolved in contact with water. This may be associated with the formation of oligomeric products due to low initiation efficiency compared to the AIBN.

Literature reports suggest that hydrogels containing NVP require high concentrations (5-20 wt \%) of crosslinker

\section{References}

1. Fechine GJM, Barros JAG and Catalani LH. Poly(N-vinyl)2-pyrrolidone) hydrogels production by ultraviolet radiation: new methodologies to accelerate crosslinking. Polymer. 2004; 45(14):4705-4709. http://dx.doi.org/10.1016/j. polymer.2004.05.006

2. Tanaka T, Fillmore D, Sun S, Nishio I, Swislow G and Shah A. Phase transition in ionic gels. Physical Review Letters. 1980; 45:1636-1639. http://dx.doi.org/10.1103/PhysRevLett.45.1636

3. Lin CC and Metters AT. Hydrogels in controlled release formulations: network design and mathematical modeling. Advanced Drug Delivery Reviews. 2006; 58(12-13):1379-1408. PMid:17081649. http://dx.doi.org/10.1016/j.addr.2006.09.004

4. O'Hagan DT, Jeffery H and Davis SS. The preparation and characterization of poly(lactide-co-glycolide) microparticles: III. Microparticle/polymer degradation rates and the in vitro release of a model protein. International Journal of Pharmaceutics. 1994; 103(1):37-45. http://dx.doi. org/10.1016/0378-5173(94)90201-1

5. Rafati H, Coombes AGA, Adler J, Holland J and Davis SS. Protein-loaded poly(-lactide-co-glycolide) microparticles for oral administration: formulation, structural and release characteristics. Journal of Controlled Release. 1997; 43(1):89-102. http://dx.doi.org/10.1016/S01683659(96)01475-7

6. Kost $\mathrm{J}$ and Langer R. Equilibrium swollen hydrogels in Controlled release applications. In: Peppas NA, editor. Hydrogels in medicine and pharmacy. Boca Raton: CRC Press; 1986. p. 95-108.

7. Pitt CG. The controlled parenteral delivery of polypeptides and proteins. International Journal of Pharmaceutics. 1990; 59(3):173-196. http://dx.doi.org/10.1016/03785173(90)90108-G to produce a material with useful mechanical properties ${ }^{12}$. Ordinarily, higher crosslinker concentrations would lead to higher crosslink density and, thus, better mechanical properties.

\section{Conclusion}

The new formulations of hydrogels allowed to obtain different properties which leads to different applications. The product of polymerization of N-vinyl-2-pyrrolidone initiated only with ammonium persulfate, was totally soluble in water, this may be associated with the formation of oligomeric products due to low initiation efficiency compared to the AIBN. The hydrogels showed good thermal stability around $200{ }^{\circ} \mathrm{C}$ and a single $\mathrm{Tg}$, indicating possibly the formation of random copolymers. The M1 sample showed a low degree of crosslinking may lead to use as absorbable material or controlled delivery of drugs. The M2 sample had a higher degree of crosslinking may potentially strengthen structure of bone cement. The M4 sample can also be used in controlled delivery of drugs, but for short periods of time, since it dissolves easily. The hydrogels studied are known for their biocompatibility, but no more specific tests were carried out to confirm such biocompatibility, which will be performed posteriorly.

8. Santos LA, Oliveira LC, Rigo ECS, Carrodeguas RG, Boschi $\mathrm{AO}$ and Arruda ACF. Influence of polymeric additives on the mechanical properties of $\alpha$-tricalcium phosphate cements. Bone. 1999; 25(2):99S-102S. http://dx.doi.org/10.1016/S87563282(99)00143-X

9. Davidenko N, Carrodeguas RG, Sastre R and San Román J. Photopolymerization of dual-setting $\alpha$-tricalcium phosphate cements. International Journal of Polymeric Materials. 2002; 51(7):577-589. http://dx.doi.org/10.1080/714975796

10. Kroschwitz JI. Polymers: biomaterials and medical applications. Nova Jersey: John Wiley \& Sons; 1989.

11. Lai YC. A novel crosslinker for UV copolymerization of $\mathrm{N}$-vinyl pyrrolidone and methacrylates to give hydrogels. Journal of Polymer Science: Part A: Polymer Chemistry. 1997; 6:1039-1046. http://dx.doi.org/10.1002/(SICI)10990518(19970430)35:6<1039::AID-POLA7>3.0.CO;2-\#

12. Peppas NA, Huang Y, Torres-Lugo M, Ward JH and Zhang J. Physicochemical foundations and structural design of hydrogels in medicine and biology. Annual Review of Biomedical Engineering. 2000; 2:9-29. PMid:11701505. http:// dx.doi.org/10.1146/annurev.bioeng.2.1.9

13. Dittgen M, Durrani M and Lehmann K. Acrylic polymers: a review of pharmaceutical applications. STP Pharma Science. 1997; 7:403-437.

14. Devine DM, Devery SM, Lyons JG, Geever LM, Kennedy JE and Higginbotham CL. Multifunctional polyvinylpyrrolidinonepolyacrylic acid copolymer hydrogels for biomedical applications. International Journal of Pharmaceutics. 2006; 326(1-2):50-59. PMid:16926073. http://dx.doi.org/10.1016/j. ijpharm.2006.07.008

15. Ozyurek C, Caykara T, Kantoglu O and Guven O. Characterization of network structure of poly(N-vinyl 2-pyrrolidone/acrylic acid) polyelectrolyte hydrogels by 
swelling measurements. Journal of Polymer Science: Part B: Polymer Physics. 2000; 38(24):3309-3317. http://dx.doi. org/10.1002/1099-0488(20001215)38:24<3309::AIDPOLB130>3.0.CO;2-H

16. Chun $\mathrm{M}$, Cho $\mathrm{C}$ and Choi $\mathrm{H}$. Characteristics of poly(vinyl pyrrolidone)/poly (acrylic acid) intermolecular complex prepared by template polymerization of acrylic acid: effect of reaction solvent and molecular weight of template. Journal of Applied Polymer Science. 2004; 94(6):2390-2394. http://dx.doi. org/10.1002/app.21176

17. Lee $\mathrm{W}$ and Chiang W. Swelling and drug-release behaviour of the poly(AA-co- vinyl pyrrolidone)/chitosan interpenetrating polymer network hydrogels. Journal of Applied Polymer Science. 2004; 91(4):2135-2142. http://dx.doi.org/10.1002/ app. 13353

18. Ameye D, Voorespoels J, Foreman P, Jasi J, Richardson P, Garesh S, et al. Ex vivo bioadhesion and in vivo testosterone bioavailability study of different bioadhesive formulations based on starch-g-poly(acrylic acid) copolymers and starch/ poly(acrylic acid) mixtures. Journal of Controlled Release. 2002; 79(1-3):173-182. http://dx.doi.org/10.1016/S01683659(01)00539-9

19. Razzak MT, Darwis D and Zainuddin S. Irradiation of polyvinyl alcohol and polyvinyl pyrrolidone blended hydrogel for wound dressing. Radiation Physics and Chemistry. 2001; 62(1):107113. http://dx.doi.org/10.1016/S0969-806X(01)00427-3

20. Risbud MV, Hardikar AA, Bhat SV and Bhonde RR. pHsensitive freeze-dried chitosan-polyvinyl pyrrolidone hydrogels as controlled release system for antibiotic delivery. Journal of Controlled Release. 2000; 68(1):23-30. http://dx.doi. org/10.1016/S0168-3659(00)00208-X

21. Marsano E, Bianchi E, Vicini S, Compagnino L, Sionkowska A, Skopinska J, et al. Stimuli responsive gels based on interpenetrating network of chitosan and poly(vinylpyrrolidone). Polymer. 2005; 46(5):1595-1600. http://dx.doi.org/10.1016/j. polymer.2004.12.017
22. Hornof M, Weyenberg W, Ludwing A and Sehnurch AB. Mucoadhesive ocular insert based on thiolated poly(acrylic acid): development and in vivo evaluation in humans. Journal of Controlled Release. 2003; 89(3):419-428. http://dx.doi. org/10.1016/S0168-3659(03)00135-4

23. Mark JE. Polymer data handbook. Oxford: Oxford University Press; 1999.

24. Wu YH and Freeman BD. Structure, water sorption, and transport properties of crosslinked N-vinyl-2-pyrrolidone/ $\mathrm{N}, \mathrm{N}$ '-methylenebisacrylamide films. Journal of Membrane Science. 2009; 344(1-2):182-189. http://dx.doi.org/10.1016/j. memsci.2009.07.050

25. Száraz I and Forsling W. A spectroscopic study of the solvation of 1-vinyl-2- pyrrolidone and poly(1-vinyl-2-pyrrolidone) in different solvents. Polymer. 2000; 41(13):4831-4839. http:// dx.doi.org/10.1016/S0032-3861(99)00705-3

26. Geever LM, Devine DM, Nugent MJD, Kennedy JE, Lyons JG and Higginbotham CL. The synthesis, characterization, phase behavior and swelling of temperature sensitive physically crosslinked poly(1-vinyl-2-pyrrolidinone)/ poly(N-isopropylacrylamide) hydrogels. Europe Polymer Journal. 2005; 42(1):69-80. http://dx.doi.org/10.1016/j. eurpolymj.2005.09.027

27. Roeges NPG. A guide to the complete interpretation of infrared spectra of organic structure. Nova Jersey: John Wiley \& Sons; 1994.

28. Devine DM and Higginbotham CL. Synthesis and $\mathrm{N}$-vinylpyrrolidinone (NVP) based hydrogels. European Polymer Journal. 2005; 41(6):1272-1279. http://dx.doi. org/10.1016/j.eurpolymj.2004.12.022

29. Sen M and Yakar A. Enhancement of copolymerization of Itaconic acid with N-vinyl 2-pyrrolidone chemically and by radiation induced cross-linking. Nuclear Instruments and Methods in Physics Research B. 2005; 234(3):226-234. http:// dx.doi.org/10.1016/j.nimb.2005.01.002 